\title{
Ein seltener Fall von Blasenausschlag in Folge von Antipyrin.
}

Vortrag, gehalten auf der Naturforscherversammlung in Bremen 1890.

Von

Hofrath Dr. Veiel in Canstatt.

\section{Meine Herren!}

Am 3. Juni 1890 trat, von seinem Hausarzte mir zugewiesen, Herr S. G. aus H., 33 Jahre alt, Kaufmann, ein Mann von kräftiger Constitution in moine Behandlung. Der Hausarzt, ein sehr erfahrener, wissenschaftlich hochstehender College, hatte die Wahrscheinlichkeitsdiagnose "Pempligus rheumaticus" gestellt.

Vor circa 6 Monaten erkrankte der vielfach von Rheumatismus leimgesuchte Patient an heftigem Kopfschmerz, gegen welchen ihm scin Hausarzt eine Medicin verordnete. Bald trat heftiges Jucken der Handteller, der Lippen, der Fusssohlen und der Glans penis hinzı. Die Lippen wurden ödematös und es bildeten sich auf denselben Blasen bis zu Bohnengrösse, ebenso zwei Blasen am harten Gaumen, und Blasen zwischen den Zehen. A n Fusssohle und Handteller traten grössere und kleinere, stark geröthete, heiss anzufühlende, glatte, gegen die Umgebung seharf begrenzte urticariaähnliche Flecken auf, die sehr stark juckten, aber nicht zur Blasenbildung führten.

Das Jucken dauerte 3-4 Tage, die Blasen an den Lippen trockneten in 4-5 Tagen, an den Zehen in circa 8 Tagen ein. Die Flecken an Handteller, Fusssohlen und Glans penis begannen nach circa 10 Tagen in grossen Fetzen abzuschuppen und waren nach 3 Wochen verschwunden. Patient fühlte sich in 
den ersten Tagen der Krankheit unbehaglich und fieberjg und blieb noch längere Zeit matt und müde.

4 Wochen nach dem ersten Anfalle erkrankte er im Jänner 1890 an Influenza mit sehr heftigen Kopfschmerzen. Er bekam A ntipyrin und nun traten ganz dieselben Erscheinungen auf, wie oben geschildert.

Mitte Februar wieder heftiger Kopfschmerz, Antipyrin und derselbe Ausstoss.

Ebenso Mitte März.

Am 24. Mai erkrankte er an einer rheumatischen Kniegelenksentzündung, zu der am 25. Mai noch heftige Kopfschmerzen hinzutraten. 11/2 Uhr Mittags: 1 Gramm Antipyrin. Nach 2 Stunden erste Anzeichen des Exanthems, das sich bis zum Abend, wie oben beschrieben entwickelte, während Kopf- und Knieschmerzen schwanden.

Am 8. Juni, also 9 Tage nach der Eruption sah ich den Patienten, der über hochgradige Nervosität und Abspannung klagt.

Die Lippen sind rauh und schuppen ab, an den Schleimhäuten von Nase und Mund nichts Abnormos nachweisbar. An der Hohlhand und zwischen den Fingern zeigen sich deutlich umschriebene, blassrothe Flecken von Errbsen- bis Zweimarkstïckgrösse, welche sich scharf durch einen stärker gerötheten Rand von der umgebenden Haut abgrenzen, Die Oberfläche glatt, trocken, nicht schuppend, nicht wärmer anzufühlen, als die umgebende Haut.

Dieselben Flecken an der Glans penis und der Fusssohle. Zwischen den Zehen vertrocknete Reste von Blasendecken, der übrige Körper frei.

Nach diesem Befunde und nach der Anamnese zweifelte ich nicht an der Diagnose eines Antipyrinexanthems und bat den Patienten die Diagnose durch das Experiment bestätigen zu dürfon.

4. Juni Morgens 8 Uhr: 1 Gramm Antipyrin, 9 Uhr: $1 / 2$ Gramm Antipyrin. 91/4 Uhr: heftiges Jucken und Brennen im After ohne Exanthem, $91 / 2$ Uhr: Prickeln in den Lippen, $10 \mathrm{Uhr}$ : Brennen in den Händen und Füssen, 11 Uhr: Lippen stark geröthet und geschwollen. Die Röthung griff von dem Lippensaume auf die äussere Haut circa $1 \mathrm{Ctm}$. weit über. 
Am harten Gaumen umschriebene, circa markstückgrosse Röthung.

Die Hände heiss anzufühlen, die alten rothen Flecken erhaben, infiltrirt, heftig juckend. Nene rothe, urticariaähnliche Flecken treten auf Hohlhand und Handrücken zu den alten hinzu. Dieselben Erscheinungen an der Eichel des Penis und auf den Fusssohlen. Heftiges Brennen zwischen den ödematös geschwollenen Zehen.

Abends 5 Uhr: Lippen, Handteller, Füsse und Penis unveräudert, auf der Stirne über der linken Augenbraue ein runder rother, nicht erhabener Fleck von 2 Ctm. Durchmesser, an der linken Unterkinngegend eine handtellergrosse Erythemstelle.

7 Uhr Abends: Das ganze Gesicht gedınsen, scharlachroth, die Lippen noch stärker gewulstet, die Conjunctiva injicirt, die Augen thränend.

Temperatur $39 \cdot 2^{\circ} \mathrm{C}$.

Die übrigen Erscheinungen unverändert. Patient fühlt sich recht krank.

5.Juni Morgens 8 Ubr: Temperatur $37^{\circ} 6^{\circ} \mathrm{C}$. Allgemeinbefinden besser. Die Scharlachrötue im Gesicht, die Injection der Conjunctiva wioder verschwunden. Hin erythomatöser Fleek ist über die ganze Lnterkinngegend ansgebreitet. Die Lippen noch dick geschwollen.

Am harten Gaumen, unmittelbar hinter den Schneidezähnen links zwei, rechts drei Blasen vou Erbsengrösse mit klarem durchsichtigen Inhalte.

Die Hitze in den Händen, an den Füssen, am Penis bat abgenommen, dio Flecken unvorändert. Am Rücken zwei kleine, haselunssgrosse Erythemstellen. Auch Abends trat kein Fieber mehr anf.

Die Blasen im Munde wurden welk und waren nach 6 Tagen ganz verschwunden. Die Lippen schwollen in 3 Tagen ab und schälten sich langsam.

Die Flecken an Händen, Füssen und am Penis schwanden nur sehr langsam im Verlaufe von 3 Wochen. Entsprechend der zweimaligen Antipyringabe am 25. Mai und 3. Juni erfolgte an denselben Stellen eine doppelte Abschälung der Epidermis in grossen Fetzen. 
Das Allgemeinbefinden besserte sich sehr rasch.

Patient blieb bis heute ganz gesund.

Auffallend bei diesem Falle ist die constante Localisation des Exanthems an Lippen, Gaumen, Händen, Penis und Füssen und die auch von anderen Beobachtern wiederholt beobachtete gleichzeitige Temperatursteigerung.

Der Fall schliesst sich eng an den auf der Bonner Klinik beobachteten, von Dr. Hahn im Centralblatt für klinische Medicin $1889 \mathrm{Nr} .49$ veröffentlichten an. 